16,18

\title{
Динамика распада водородных кластеров на поверхности графена и стоун-уэльсовского графена
}

\author{
(C) А.И. Подливаев ${ }^{1,2}$ \\ ${ }^{1}$ Национальный исследовательский ядерный университет „МИФИ“, \\ Москва, Россия \\ ${ }^{2}$ Научно-исследовательский институт проблем развития научно-образовательного потенциала молодежи, \\ Москва, Россия \\ E-mail: AIPodlivayev@mephi.ru
}

Поступила в Редакцию 27 августа 2020 г.

В окончательной редакции 27 августа 2020 г.

Принята к публикации 30 августа 2020 г.

Методом молекулярной динамики изучается термическая устойчивость водородных кластеров, расположенных на поверхности графена и стоун-уэльсовского графена - недавно открытого аллотропа графена. Исследованы пяти, шести и семиатомные водородные кольца, а также компактные скопления из шестнадцати атомов водорода, адсорбированных на данных углеродных структурах. Определены каналы распада водородных кластеров и температурные зависимости времени их жизни. Найдены значения энергий активации и частотных факторов в законе Аррениуса.

Ключевые слова: углерод, графен, водород, устойчивость, молекулярная динамика.

DOI: 10.21883/FTT.2020.12.50223.177

\section{1. Введение}

Создание методом дефолиации монослоя графитаграфена [1] с аномально высокой проводимостью [2] и прочностью [3] стимулировало поиск его аллотропов, а также детальное изучение свойств этого материала. Допированием квазидвумерных углеродных структур атомами иных элементов были синтезированы графан [4], графин [5], графдин [6], диаман на подложке $\mathrm{SiC}$ (0001) [7] и фторированный алмаз (F-диаман) на подложке $\mathrm{CuNi}(111)$ [8]. В рамках различных теоретических моделей было предсказано множество двумерных углеродных структур (смотри, например, работы [9-16]).

Только за последние два года синтезировано квазидвумерное вещество - композит полианилина и оксида графена [17] и были предсказаны $\psi$-графен [18], РВСF-графен [19], М-графен [20], азуграфен (azugraphene [21]) и стоун-уэльсовский графен [22].

Интерес к стоун-уэльсовскому графену в настоящей работе обусловлен тем, что это вещество обладает термодинамической устойчивостью, превышающей устойчивость всех известных ранее аллотропов, уступая в этой характеристике только исходному графену, и его энергия выше энергии графена на величину $0.149 \mathrm{eV} /$ atom. Ближайший к нему по энергии связи азуграфен [21] энергетически менее выгоден на величину $16 \mathrm{meV} /$ atom. Стоун-уэльсовский графен может быть представлен как графен с периодически расположенными в нем дефектами Стоуна-Уэльса (StoneWales, SW [23]). Элементарная ячейка данного аллотропа может быть получена из соответствующей ячейки графена путем трансформации Стоуна-Уэльса при по- вороте одной связи на угол 90. Авторами работы [22] новый материал был назван SW-графеном. Элементарная ячейка $\mathrm{SW}$-графена и соответствующая ячейка графена, состоящие из 16 атомов углерода, представлены на рис. $1, b$ и $1, a$, соответственно.

Насыщение водородом углеродных структур существенно изменяет их механические и электронные характеристики. Полное двустороннее гидрирование графена и SW-графена, обладающих высокой проводимостью, превращает их в диэлектрический графан [4] и SW-графан [24]. По данным работ [25] и [26], ширина запрещенной зоны в графане $E_{g}=5.4$ и $5.34 \mathrm{eV}$ соответственно. При полном и частичном гидрировании $\psi$-графена [27] образуются устойчивые диэлектрические структуры с шириной запрещенной зоны, сопоставимой с шириной запрещенной зоны графана. B SW-графане и графане величины $E_{g}$ практически совпадают [24]. Термическая устойчивость границы раздела

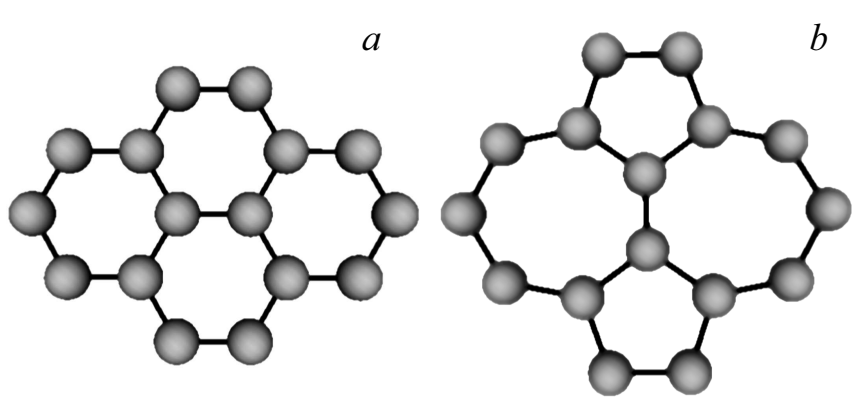

Рис. 1. Элементарные ячейки $\mathrm{C}_{16}$ графена $(a)$ и $\mathrm{SW}$-графена $(b)$. Жирной чертой отмечена $\mathrm{C}-\mathrm{C}$-связь, поворот которой на $90^{\circ}$ приводит к образованию дефекта Стоуна-Уэльса. 
графен-графан [28] делает возможным формирование устойчивых диэлектрических областей на поверхности графена, что может найти применение, например, при создания резонансно-туннельных структур в элементах современной электроники [29]. В работе [28] показано, что диффундирующий по поверхности графена атом водорода притягивается к массиву гидрированного графена, и это обеспечивает термическую устойчивость макроскопической области гидрированного графена.

Термическая устойчивость малых гидрированных областей на поверхностях графена и $\mathrm{SW}$-графена была исследована в работе [30]. Основными объектами исследования в этой работе были шестиатомное гидрированное кольцо на поверхности графена, а также пяти, шести и семиатомные кольца на поверхности SW-графена. Было показано, что эти водородные кластеры термически устойчивы при температурах близких к комнатной. Термическая устойчивость в работе [30] была исследована методом статического моделирования, при котором из физических соображений выбирается наиболее вероятный путь распада, и определяется потенциальный барьер, отделяющий исходную структуру от продуктов распада. Достоинством такого подхода является высокая точность определения энергии активации выбранного канала распада, а основным недостатком - необходимость перебора множества каналов для определения пути распада с минимальной энергией активации. Альтернативным методу статического моделирования является метод молекулярной динамики (ММД), позволяющий исследовать эволюцию нагретой до определенной температуры атомной системы в режиме реального времени вплоть до распада этой системы. Такой подход позволяет определить, во-первых, температурную зависимость времени жизни системы, а также энергию активации распада, и, во-вторых, наиболее вероятные каналы термического распада.

Основной целью представленной работы является определение методом молекулярной динамики термической устойчивости водородных колец и более крупных водородных кластеров на поверхности графена и SW-графена.

\section{2. Методы расчета}

Для моделирования графена и SW-графена использованы сверхъячейки $\mathrm{C}_{144}$, состоящие из 9 примитивных ячеек аналогичные тем, которые были исследованы в работе [30]. Соответствующие элементарные ячейки $\mathrm{C}_{16}$ представлены на рис. $1, a$ и $b$, а сверхъячейки $\mathrm{C}_{144}-$ на рис. 2. Граничные условия были периодическими в двух планарных направлениях $(x, y)$ и свободными в поперечном направлении $z$. Периоды сверхъячеек определялись из условия минимума потенциальной энергии при релаксации по координатам всех атомов.

Динамическое моделирование цепочек проводилось в рамках микроканонического ансамбля [31], в котором
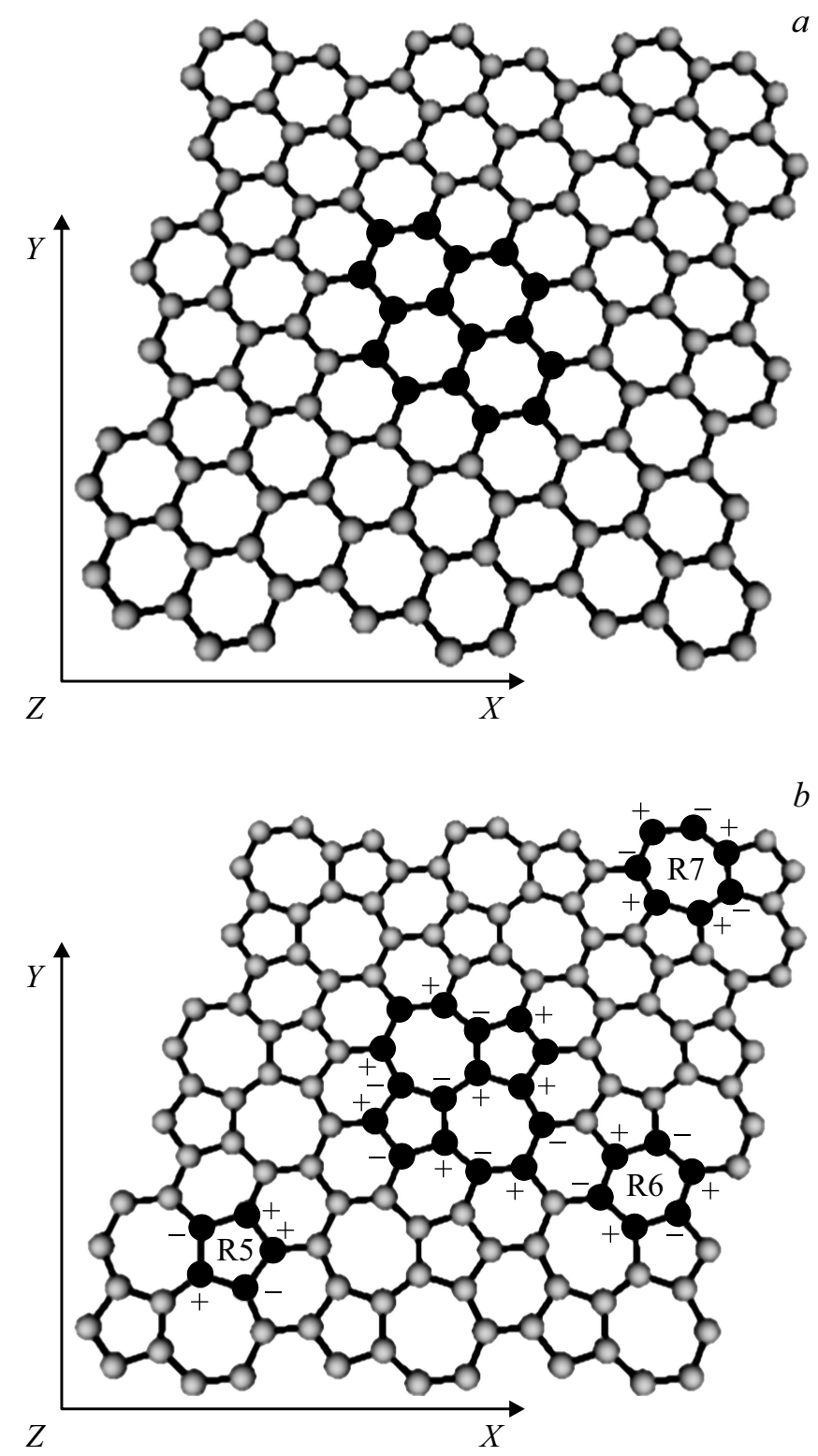

Рис. 2. Расчетные сверхъячейки $\mathrm{C}_{144}$ графена $(a)$ и SW-графена $(b)$ с отмеченными на них областями гидрирования. Черным цветом отмеченыатомы углеродного остова, образующие ковалентную связь с атомами водорода.

сумма потенциальной и кинетической энергии сохраняется при движении атомов. В качестве исходной выбиралась равновесная атомная конфигурация (см. рис. 2, a и $b$ ). Начальные скорости атомов подчинялись распределению Максвелла с различными температурами. Роль температуры в микроканоническом ансамбле играет так называемая микроканоническая температура $T_{m}$, определяемая по формуле $[32,33]\left\langle E_{k i n}\right\rangle=k_{\mathrm{B}} T_{m}(3 n-3) / 2$, где $\left\langle E_{k i n}\right\rangle-$ усредненная по времени кинетическая энергия системы, $n-$ число атомов в ней, $k_{\mathrm{B}}$ - постоянная Больцмана, $(3 n-3)$ - число кинетических степеней свободы планарной системы с периодическими граничными условиями. Полагается, что значение полного импульса 
системы равно нулю. Этот подход известен как „теория ограниченного теплового резервуара“ (finite heat bath theory) [34,35]. В рамках этой теории среднее время жизни - изолированной системы определяется следующим приближенным аналогом формулы Аррениуса [34,35]:

$$
\tau^{-1}\left(T_{m}\right) \approx A \exp \left(-E_{g} /\left(k_{\mathrm{B}} T^{*}\right)\right),
$$

где $A$ - частотный фактор, $E_{a}$ - энергия активации, $T^{*}=T_{m}-E_{a} / 2 C, C=(3 n-3) k_{\mathrm{B}}-$ микроканоническая теплоемкость.

Межатомные взаимодействия описывались в рамках неортогональной модели сильной связи [36], менее точной, чем методы ab-initio, но превосходящей их по скорости счета. При этом данная модель демонстрирует хорошее согласование с методиками, основанными на теории функционала плотности, для систем, содержащих атомы углерода в состояниях с различными типами гибридизации [37]. Кроме того, она успешно применялась для исследования термической устойчивости кластеров $\mathrm{C}_{20}$, графеновых и других углеродных систем (см. работы [38-43] и ссылки в них). Программная реализация на языке FORTRAN межатомного потенциала [36] опубликована в работе [44]. В этой программе представлен инструментарий, необходимый для атомистических расчетов - определение межатомных сил, поиск стационарных точек (локальных минимумов и седловых точек) на поверхности потенциальной энергии в пространстве обобщенных координат атомов, определение электронного и фононного спектра изучаемого кластера, и различные модификации ММД.

Для найденных межатомных сил уравнения движения Ньютона решались численно методом скоростей Верле (аналог метода Штёрмера второго порядка точности) с шагом по времени $0.3 \mathrm{fs}$.

Была исследована временная эволюция следующих углеводородных систем: первая структура на основе графена описывается химической формулой $\mathrm{C}_{144} \mathrm{H}_{6}$. и представлена на рис. 2, а атомами черного цвета. В данной структуре 6 атомов водорода ковалентно связаны с шестиатомным кольцом $s p^{3}$-гибридизованных атомов углерода. При этом, атомы водорода, связанные с соседними атомами углеродного кольца расположены по разные стороны графеновой основы. Структура с таким расположением шести атомов водорода термодинамически наиболее устойчива (обладает минимальной потенциальной энергией).

Вторая структура с химической формулой $\mathrm{C}_{144} \mathrm{H}_{16}$. на основе графена также представлена на центральной части рис. 2, a атомами черного цвета. Плотное скопление атомов водорода и связанных с ними $s p^{3}$-гибридизованных атомов углерода является, фактически, островком графана [4] на графеновой плоскости. Характер двустороннего расположения (чередования) атомов водорода на графеновой основе аналогичен предыдущей структуре.

Третья, четвертая, пятая и шестая структуры с химическими формулами $\mathrm{C}_{144} \mathrm{H}_{5}, \mathrm{C}_{144} \mathrm{H}_{6}, \mathrm{C}_{144} \mathrm{H}_{7}$ и $\mathrm{C}_{144} \mathrm{H}_{16}$ соответственно, формируются на основе SW-графена. Третья, четвертая и пятая структуры представляют собой гидрированные пяти, шести и семиатомные кольца на поверхности SW-графена. Схематические изображения этих колец на рис. 2, $b$ отмечены символами R5, R6 и R7. Шестая структура с химической формулой $\mathrm{C}_{144} \mathrm{H}_{16}$ на основе $\mathrm{SW}$-графена представлена на центральной части рис. 2, $b$ атомами черного цвета. Плотное скопление атомов водорода и связанных с ними $s p^{3}$-гибридизованных атомов углерода является островком SW-графана [24] на плоскости SW-графена. Знаками „+“ („-“) на рис. 2,b отмечены атомы углеродной основы, образующие ковалентную связь с атомами водорода, которые расположены над (под) SW-графеновой „Плоскостью“.

Временна́я эволюция перечисленных структур была исследована при температурах $T_{m}=2000,2500,3000$, 3500 и $4000 \mathrm{~K}$. Расчет движения каждой атомной структуры при фиксированной температуре проводился для четырех различных вариантов начальных распределений скоростей и смещений атомов вПлоть до термического распада. Изучаемая углеводородная система считалась распавшейся, когда один из атомов водорода в процессе эволюции удалялся на расстояние более $5 \AA$ от атома углеродной основы, с которым он исходно образовывал ковалентную связь.

\section{3. Результаты и их обсуждение}

\section{1. Каналы распада графеновых систем $\mathrm{C}_{144} \mathrm{H}_{6}$ и $\mathrm{C}_{144} \mathrm{H}_{16}$}

При распаде углеводородных систем $\mathrm{C}_{144} \mathrm{H}_{6}$ и $\mathrm{C}_{144} \mathrm{H}_{16}$ на основе графена было обнаружено три канала термического распада этих систем - поверхностная диффузия атомов водорода без отрыва их от графеновой основы, десорбция атомарного водорода и десорбция молекулярного водорода. В некоторых случаях наблюдался распад сразу по нескольким каналам (например, поверхностная диффузия и десорбция атомарного водорода). Термического распада углеродной основы не наблюдалось. Количество распадов систем $\mathrm{C}_{144} \mathrm{H}_{6}$ и $\mathrm{C}_{144} \mathrm{H}_{16}$ по различным каналам и при различных температурах представлено в табл. 1.

Из данных табл. 1 следует, что преобладающим каналом распада конфигурации с шестиатомным кольцом является поверхностная диффузия (12 распадов при всех температурах). Вероятность десорбции атомарного водорода несколько ниже (8 распадов), что соответствует результатам работы [30]. Для системы $\mathrm{C}_{144} \mathrm{H}_{16}$ вероятности распадов по каналам поверхностной диффузии и десорбции атомарного водорода практически равны (7 и 6 распадов соответственно), при этом существенно, более чем в три раза, возрастает вероятность десорбции молекулярного водорода. Тенденцию к десорбции молекул $\mathrm{H}_{2}$ можно объяснить тем, что в системе $\mathrm{C}_{144} \mathrm{H}_{16}$ поверхностная диффузия затруднена, поскольку некоторые 
Таблица 1. Количество распадов водородных кластеров на поверхности графена по различным каналам

\begin{tabular}{c|l|c|c|c|c|c}
\hline \multirow{2}{*}{ Кластер } & \multirow{2}{*}{ Канал } & \multicolumn{5}{|c}{$T(\mathrm{~K})$} \\
\cline { 3 - 8 } & & 2000 & 2500 & 3000 & 3500 & 4000 \\
\hline \multirow{3}{*}{$\mathrm{C}_{144} \mathrm{H}_{6}$} & Поверхностная диффузия & 3 & 3 & 1 & 3 & 2 \\
\cline { 2 - 8 } & Десорбция атома $\mathrm{H}$ & 1 & 1 & 2 & 2 & 2 \\
\cline { 2 - 7 } & Десорбция молекулы $\mathrm{H}_{2}$ & 0 & 0 & 2 & 0 & 0 \\
\hline \multirow{2}{*}{$\mathrm{C}_{144} \mathrm{H}_{16}$} & Поверхностная диффузия & 3 & 2 & 1 & 1 & 0 \\
\cline { 2 - 7 } & Десорбция атома Н & 0 & 2 & 1 & 2 & 1 \\
\cline { 2 - 7 } & Десорбция молекулы $\mathrm{H}_{2}$ & 1 & 0 & 2 & 1 & 3
\end{tabular}

атомы водорода окружены соседними атомами водорода, что препятствует перескоку их на соседний узел. Это же обстоятельство способствует увеличению вероятности образования водородных пар.

\section{2. Каналы распада систем на основе SW-графена}

При распаде углеводородных систем $\mathrm{C}_{144} \mathrm{H}_{5}, \mathrm{C}_{144} \mathrm{H}_{6}$, $\mathrm{C}_{144} \mathrm{H}_{7}$ и $\mathrm{C}_{144} \mathrm{H}_{16}$ на основе $\mathrm{SW}$-графена было обнаружено четыре канала термического распада. Три из них совпадают с каналами распада графеновых систем - это поверхностная диффузия атомов водорода без отрыва их от графеновой основы, десорбция атомарного водорода, десорбция молекулярного водорода. Четвертым каналом (отсутствующим в структурах на основе графена) является распад углеродного каркаса SW-графена.

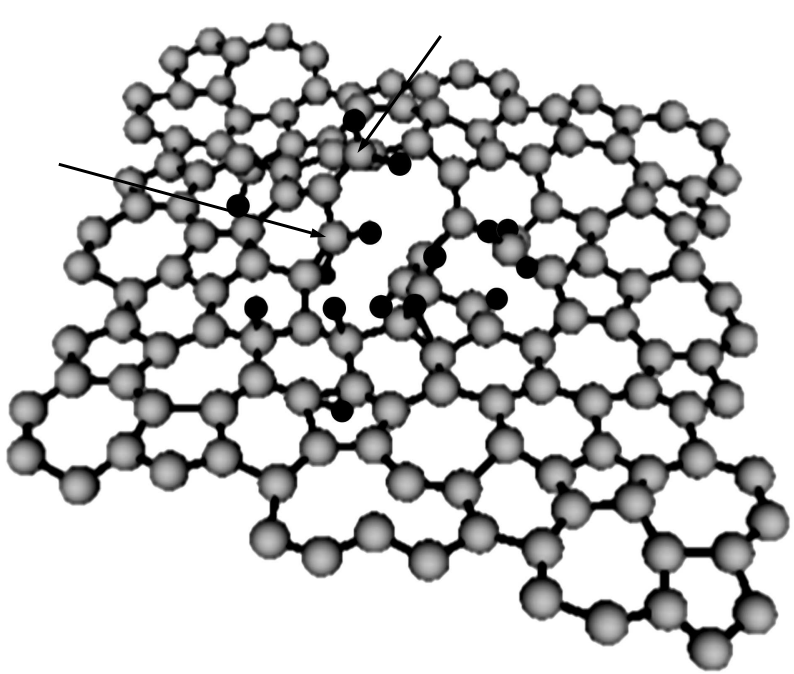

Рис. 3. Структура $\mathrm{C}_{144} \mathrm{H}_{16}$ на основе $\mathrm{SW}$-графена после распада углеродного каркаса при температуре $3500 \mathrm{~K}$. Маленькими черными шариками обозначены атомы водорода. Стрелками отмечены атомы углерода, которые образуют ковалентную связь с двумя атомами водорода.
Распад углеродного каркаса SW-графена и отсутствие такого распада в графеновых структурах объясняется различием в температурной устойчивости графена и $\mathrm{SW}$-графена. Температура плавления SW-графена равна $3500 \mathrm{~K}$ [41], а температура плавления графена, определенная в рамках различных подходов лежит в интервале 4500-5100 K [45-47].

Формы распадов каркаса в структурах $\mathrm{C}_{144} \mathrm{H}_{5}, \mathrm{C}_{144} \mathrm{H}_{6}$, $\mathrm{C}_{144} \mathrm{H}_{7}$ и $\mathrm{C}_{144} \mathrm{H}_{16}$ не существенно различаются между собой и заключаются в разрыве одной или нескольких близких $\mathrm{C}-\mathrm{C}$ связей. Характерный пример такого повреждения представлен на рис. 3. На этом рисунке виден разрыв в виде многоатомного кольца. Края разрыва расходятся в различные стороны от исходной SW-графеновой плоскости. Принципиальной особенность всех наблюдаемых разрывов является их локализация в области исходного гидрирования структуры. Атомы водорода ослабляют ближайшие к ним С-C связи. Этот результат коррелирует с выводами работ $[48,49]$ о снижении прочности $\mathrm{C}-\mathrm{C}$ связи адсорбированным водородом. Расчеты, проведенные в работе [48] были выполнены с использованием теории функционала плотности (DFT), а работе [49] — в рамках неортогональной модели сильной связи [36].

Еще одной особенностью, часто встречающейся в разрывах, является перераспределение атомов водорода при котором к атому углеродной основы, находящемуся

Таблица 2. Количество распадов водородных кластеров на поверхности SW-графена по различным каналам

\begin{tabular}{|c|c|c|c|c|c|c|}
\hline \multirow{2}{*}{ Кластер } & \multirow{2}{*}{ Канал } & \multicolumn{5}{|c|}{$T(\mathrm{~K})$} \\
\hline & & 2000 & 2500 & 3000 & 3500 & 4000 \\
\hline \multirow{4}{*}{$\mathrm{C}_{144} \mathrm{H}_{5}$} & Поверхностная диффузия & 4 & 1 & 2 & 1 & 1 \\
\hline & Десорбция атома Н & 0 & 1 & 0 & 1 & 1 \\
\hline & Десорбция молекулы $\mathrm{H}_{2}$ & 0 & 1 & 0 & 1 & 0 \\
\hline & Распад каркаса $\mathrm{C}_{144}$ & 0 & 1 & 2 & 2 & 2 \\
\hline \multirow{4}{*}{$\mathrm{C}_{144} \mathrm{H}_{6}$} & Поверхностная диффузия & 1 & 3 & 1 & 0 & 2 \\
\hline & Десорбция атома Н & 1 & 0 & 1 & 3 & 2 \\
\hline & Десорбция молекулы $\mathrm{H}_{2}$ & 0 & 0 & 1 & 1 & 0 \\
\hline & Распад каркаса $\mathrm{C}_{144}$ & 2 & 1 & 1 & 0 & 0 \\
\hline \multirow{4}{*}{$\mathrm{C}_{144} \mathrm{H}_{7}$} & Поверхностная диффузия & 2 & 1 & 2 & 0 & 0 \\
\hline & Десорбция атома Н & 1 & 1 & 2 & 3 & 2 \\
\hline & Десорбция молекулы $\mathrm{H}_{2}$ & 1 & 2 & 0 & 0 & 1 \\
\hline & Распад каркаса $\mathrm{C}_{144}$ & 0 & 0 & 0 & 1 & 1 \\
\hline \multirow{4}{*}{$\mathrm{C}_{144} \mathrm{H}_{16}$} & Поверхностная диффузия & 2 & 1 & 1 & 1 & 0 \\
\hline & Десорбция атома H & 1 & 2 & 1 & 0 & 0 \\
\hline & Десорбция молекулы $\mathrm{H}_{2}$ & 1 & 0 & 2 & 1 & 3 \\
\hline & Распад каркаса $\mathrm{C}_{144}$ & 0 & 1 & 0 & 2 & 3 \\
\hline
\end{tabular}


Таблица 3. Характеристики термического распада углеводородных систем $\mathrm{C}_{144} \mathrm{H}_{N}(N=5,6,7,16)$ на основе графена и SW-графен

\begin{tabular}{c|c|c|c|c|c}
\hline & № & $E_{a}, \mathrm{eV}$ & $A \cdot 10^{-13}, \mathrm{~s}^{-1}$ & $\tau(T=77 \mathrm{~K}), \mathrm{s}$ & $\tau(T=273 \mathrm{~K}), \mathrm{s}$ \\
\hline \multirow{3}{*}{ Графен } & 6 & $\begin{array}{c}0.89 \pm 0.14 \\
1.61^{*}[30]\end{array}$ & $3.6 \pm 0.5$ & $5 \cdot 10^{44}$ & $0.7 \cdot 10^{3}$ \\
& 16 & $0.82 \pm 0.15$ & $3.2 \pm 0.5$ & $1.4 \cdot 10^{40}$ & 43 \\
\cline { 2 - 6 } & 5 & $\begin{array}{c}1.00 \pm 0.11 \\
1.25^{*}[30]\end{array}$ & $3.8 \pm 0.4$ & $7 \cdot 10^{51}$ & $8 \cdot 10^{4}$ \\
\cline { 2 - 6 } SW-графен & 6 & $\begin{array}{c}1.35 \pm 0.19 \\
1.36^{*}[30]\end{array}$ & $27 \pm 5$ & $8 \cdot 10^{73}$ & $3 \cdot 10^{10}$ \\
\cline { 2 - 6 } & 7 & $\begin{array}{c}0.99 \pm 0.23 \\
1.27^{*}[30]\end{array}$ & $9.5 \pm 2.3$ & $6 \cdot 10^{50}$ & $2 \cdot 10^{4}$ \\
\cline { 2 - 6 } & 16 & $1.04 \pm 0.14$ & $7.2 \pm 1.0$ & $2 \cdot 10^{54}$ & $2 \cdot 10^{5}$
\end{tabular}

Пр имечан ие. Символом „*“ отмечены значения энергий активации, полученные в работе [30] методом статического моделирования.

на границе разрыва, присоединяются два атома водорода (происходит спонтанная пассивация границы разрыва). Два атома углерода с такой пассивацией отмечены стрелками на рис. 3 .

Количество распадов данных систем по различным каналам при различных температурах представлено в табл. 2. Из данных таблицы видно, что вероятности распадов по различным каналам различаются не очень сильно. Это позволяет проводить качественную оценку температурной зависимости времени жизни данных структур безотносительно к отдельным каналам термического распада.

\section{3. Температурная зависимость времени жизни структур}

На рис. 4-6 представлена зависимость логарифма времени жизни изучаемых структур от обратной температуры. Приближение методом наименьших квадратов температурной зависимости времени жизни аррениусовской экспонентой (1) позволяет определить энергии активации и частотные факторы термического распада. Соответствующие аррениусовские зависимости представлены на рис. 4-6 сплошными и пунктирными линиями. В табл. 3 представлены энергии активации и частотные факторы, полученные по данным рис. 4-6, а также энергии активации, полученных в работе [30] методом статического моделирования. Потенциал межатомного взаимодействия, граничные условия исходных структур в данной работе и в работе [30] идентичны. Однако, метод статического моделирования, применяемый в работе [30] позволил изучить только каналы распада, связанные с перемещением одного атома водорода в то время как ММД позволяет определить любой возможный канал. Сопоставление энергий активации, полученных в данной работе и в работе [30], а также данные табл. 1 и 2 показывает, что удаление одиночного

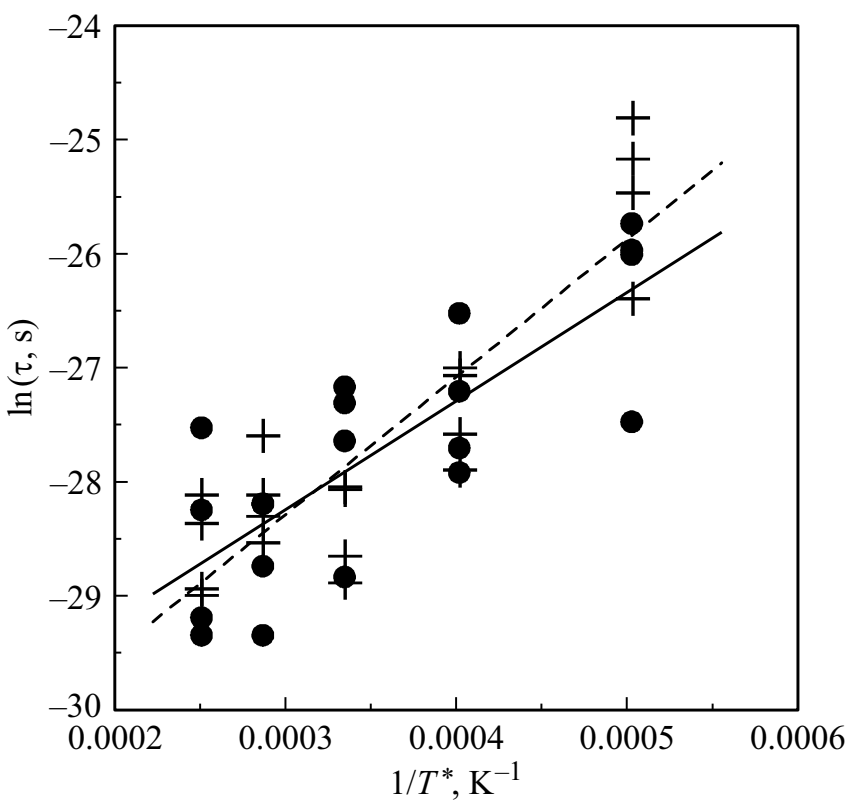

Рис. 4. Зависимость времени жизни $\tau$-структур $\mathrm{C}_{144} \mathrm{H}_{16}$ на основе графена и SW-графена от обратной температуры $T^{*}$ (см. текст). Кружки и крестики - результаты численного счета для структур $\mathrm{C}_{144} \mathrm{H}_{16}$ на основе графена и $\mathrm{SW}$-графена соответственно. Сплошная и пунктирная линии - линейная аппроксимация методом наименьших квадратов для графена и SW-графена соответственно.

атома водорода не является преобладающим каналом распада.

Аррениусовская экстраполяция позволяет качественно оценить времена жизни данных структур при низких температурах, недоступных для прямого моделирования. В табл. 3 представлены соответствующие времена жизни при температурах жидкого азота и замерзании воды. Из данных этой таблицы видно, что при температуре жидкого азота времена жизни всех структур являются 


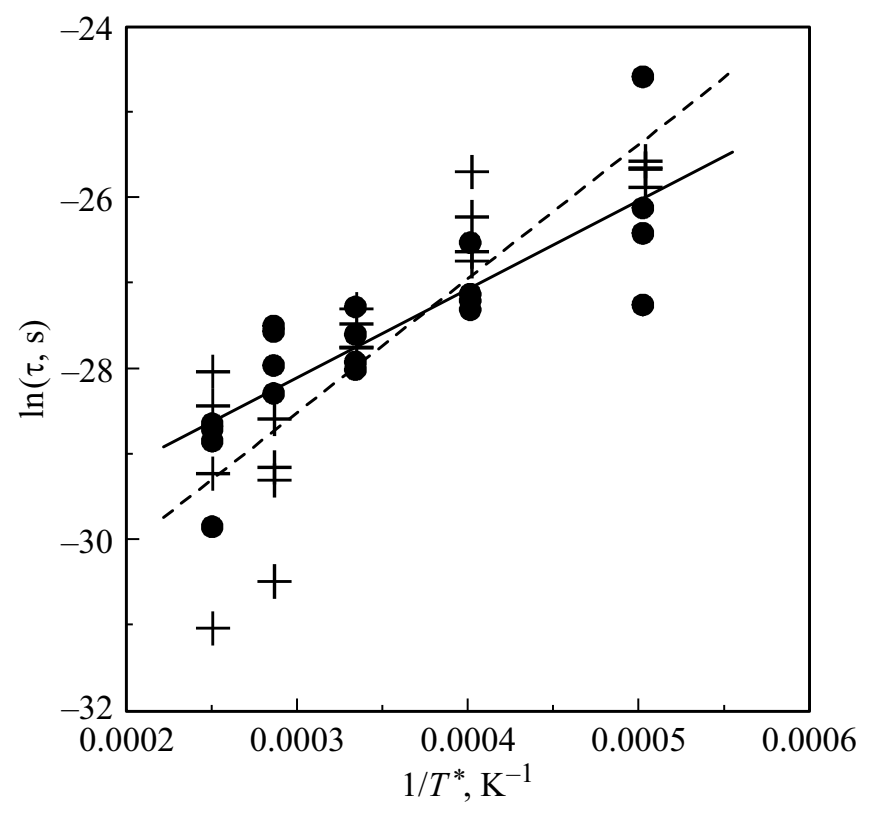

Pис. 5. То же, что на рис. 4 , для структур $\mathrm{C}_{144} \mathrm{H}_{6}$ на основе графена и SW-графена.

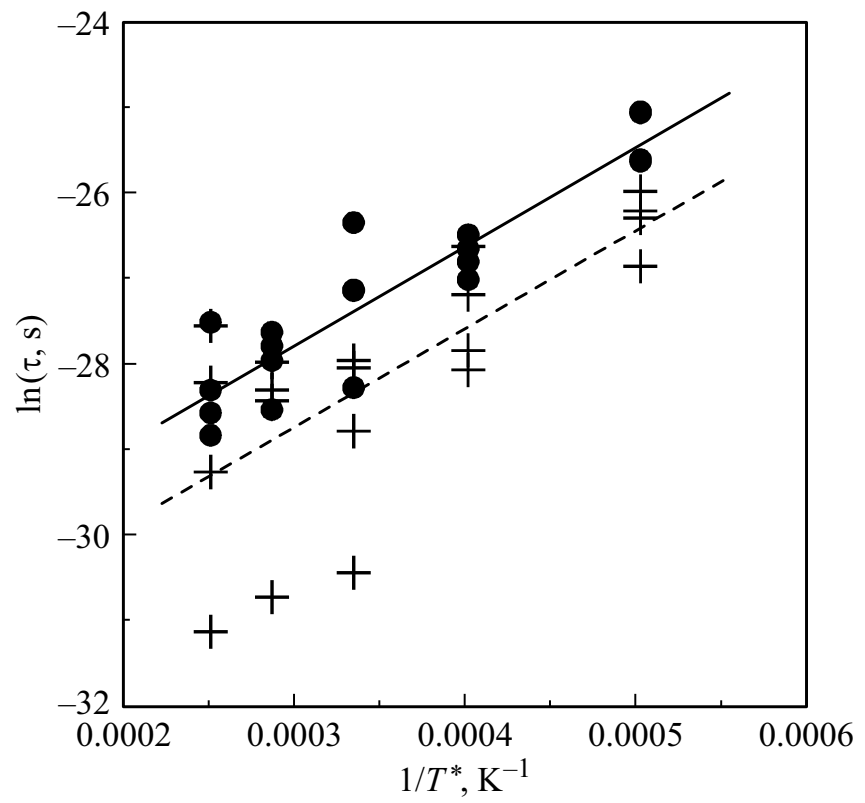

Рис. 6. То же, что на рис. 4, для структур $\mathrm{C}_{144} \mathrm{H}_{5}$ и $\mathrm{C}_{144} \mathrm{H}_{7}$ на основе SW-графена. Кружки и сплошная линия соответствуют структуре $\mathrm{C}_{144} \mathrm{H}_{5}$, а крестики и пунктирная линия - структуре $\mathrm{C}_{144} \mathrm{H}_{7}$.

макроскопическими. Однако, только структура $\mathrm{C}_{144} \mathrm{H}_{6}$ $\mathrm{SW}$-графена обладает достаточной устойчивостью для приложений в графеновой электронике при температуре близкой к комнатной.

\section{4. Заключение}

В настоящей работе термическая устойчивость углеводородных структур $\mathrm{C}_{144} \mathrm{H}_{n}(n=5,6,7,16)$ на основе графена и изучена путем динамического компьютерного моделирования в широком диапазоне температур. Определены температурные зависимости времен жизни $\tau$ этих кластеров до момента их распада и типы каналов распада. Установлено, что температурная устойчивость данных структур, полученная при моделировании в реальном времени, ниже, чем устойчивость, предсказанная ранее в рамках упрощенной модели статического моделирования. При температуре жидкого азота эти структуры достаточно устойчивы для применения их в качестве элементов графеновой электроники. Однако при температурах близких к комнатной, достаточной устойчивостью обладает только шестиатомное водородное кольцо на поверхности SW-графена. При этом полученные результаты свидетельствуют о том, что для целей аккумуляции водорода в водородной энергетике, где необходимо обратимое накопление/выделение водорода структуры на основе графена и SW-графена вполне пригодны. Более перспективным для этого применения представляется графен, поскольку в отличие от SW-графена в нем при высоких температурах наблюдается только десорбция водорода без плавления углеродной основы.

\section{Финансирование работы}

Работа поддержана Российским фондом фундаментальных исследований (грант № 18-02-00278-a) и выполнена при поддержке Министерства науки и высшего образования РФ в рамках Программы повышения конкурентоспособности Национального исследовательского ядерного университета „МИФИ““.

\section{Конфликт интересов}

Автор заявляет, что у него нет конфликта интересов.

\section{Список литературы}

[1] K.S. Novoselov, A.K. Geim, S.V. Morozov, D. Jiang, Y. Zhang, S.V. Dubonos, I.V. Grigorieva, A.A. Firsov. Science 306, 666 (2004).

[2] K.S. Novoselov, A.K. Geim, S.V. Morozov, D. Jiang, M.I. Katsnelson, I.V. Grigorieva, S.V. Dubonos, A.A. Firsov. Nature 438, 197 (2005).

[3] А.Е. Галашев, О.Р. Рахманова. УФН 184, 1045 (2014).

[4] J.O. Sofo, A.S. Chaudhari, G.D. Barber. Phys. Rev. B 75, 153401 (2007).

[5] D.C. Elias, R.R. Nair, T.M.G. Mohiuddin, S.V. Morozov, P. Blake, M.P. Halsall, A.C. Ferrari, D.W. Boukhvalov, M.I. Katsnelson, A.K. Geim, K.S. Novoselov. Science 323, 610 (2009).

[6] Y. Li, L. Xu, H. Liu, Y. Li. Chem. Soc. Rev. 43, 2572 (2014).

[7] Y. Gao, T. Cao, F. Cellini, C. Berger, W.A. de Heer, E. Tosatti, E. Riedo, A. Bongiorno. Nature Nanotechnology 13, 133 (2018). 
[8] P.V. Bakharev, M. Huang, M. Saxena, S.W. Lee, S.H. Joo, S.O. Park, J. Dong, D. Camacho-Mojica, S. Ji, Y. Kwon, M. Biswal, F. Ding, S.K. Kwak, Z. Lee, R.S. Ruoff. $2019-$ arxiv.org https://arxiv.org/ftp/arxiv/papers/1901/1901.02131.pdf

[9] Л.А. Чернозатонский, П.Б. Сорокин, А.Г. Квашнин, Д.Г. Квашнин. Письма в ЖЭТФ 90, 144 (2009).

[10] J. Zhou, Q. Wang, Q. Sun, X.C. Chen, Y. Kawazoe, P. Jena. Nano Lett. 9, 3867 (2009).

[11] X.-L. Sheng, H.-J. Cui, F. Ye, Q.-B. Yan, Q.-R. Zheng, G. Su. J. Appl. Phys. 112, 074315 (2012).

[12] Y. Liu, G. Wang, Q. Huang, L. Guo, X. Chen. Phys. Rev. Lett. 108, 225505 (2012).

[13] Z. Wang, X.-F. Zhou, X. Zhang, Q. Zhu, H. Dong, M. Zhao, A.R. Oganov. Nano Lett. 15, 6182 (2015).

[14] S. Zhang, J. Zhou, Q. Wang, X. Chen, Y. Kawazoe, P. Jena. Proc. Nature Acad. Sci. 112, 2372 (2015).

[15] Е.А. Беленков, В.В. Мавринский, Т.Е. Беленкова, В.М. Чернов. ЖЭТФ 147, 949 (2015).

[16] H. Einollahzadeh, S.M. Fazeli, R.S. Dariani. Sci. Technol. Adv. Mater 17, 610 (2017).

[17] G.M. de Araújo, L. Codognoto, F.R. Simões. J. Solids State Electrochem. (2020). https://doi.org/10.1007/s10008-020-04517-1

[18] X. Li, Q. Wang, P. Jena. J. Phys. Chem. Lett. 8, 3234 (2017).

[19] W. Zhang, C. Chai, Q. Fan, Y. Song, Y. Yang. Chem. NanoMater 6, 139 (2020).

[20] C. Kou, Y. Tian, M. Zhang, E. Zurek, X. Qu, X. Wang, K. Yin, Y. Yan, L. Gao, M. Lu, W. Yang. 2D-Mater. 7, 025047 (2020).

[21] J. Liu, H. Lu. RSC Adv. 9, 34481 (2019).

[22] H. Yin, X. Shi, C. He, M. Martinez-Canales, J. Li, C.J. Pickard, C. Tang, T. Ouyang, C. Zhang, J. Zhong. Phys. Rev. B 99, 041405 (2019).

[23] A.J. Stone, D.J. Wales. Chem. Phys. Lett. 128, 501 (1986).

[24] А.И. Подливаев. Письма в ЖЭТФ 110, 692 (2019).

[25] S. Lebègue, M. Klintenberg, O. Eriksson, M.I. Katsnelson. Phys. Rev. B 79, 245117 (2009).

[26] А.И. Подливаев, Л.А. Опенов. Письма в ЖЭТФ 106, 98 (2017).

[27] X. Huang, M. Ma, L. Cheng, L. Liu. Physica E 115, 113701 (2020).

[28] Л.А. Опенов, А.И. Подливаев. Письма в ЖЭТФ 90, 505 (2009).

[29] Л.А. Чернозатонский, П.Б. Сорокин, Е.Э. Белова, Й. Брюнинг, А.С. Федоров. Письма в ЖЭТФ 85, 84 (2007).

[30] А.И. Подливаев. Письма в ЖЭТФ, 111, 728 (2020).

[31] E.M. Pearson, T. Halicioglu, W.A. Tiller. Phys. Rev. A 32, 3030 (1985).

[32] C. Xu, G.E. Scuseria. Phys. Rev. Lett. 72, 669 (1994).

[33] J. Jellinek, A. Goldberg. J. Chem. Phys. 113, 2570 (2000).

[34] C.E. Klots. Z. Phys. D 20, 105 (1991).

[35] J.V. Andersen, E. Bonderup, K. Hansen. J. Chem. Phys. 114, 6518 (2001).

[36] M.M. Maslov, A.I. Podlivaev, K.P. Katin. Mol. Simulation 42, 305 (2016)

[37] K.P. Katin, M.M. Maslov. J. Phys. Chem. Solids 108, 82 (2017).

[38] K.P. Katin, S.A. Shostachenko, A.I. Avhadieva, M.M. Maslov, Adv. Phys. Chem. 2015, 506894 (2015).

[39] А.И. Подливаев, Л.А. Опенов. ФТТ 60, 160 (2018).

[40] Л.А. Опенов, А.И. Подливаев. ФТТ 60, 795 (2018).
[41] Л.А. Опенов, А.И. Подливаев. Письма в ЖЭТФ 109, 746 (2019).

[42] Л.А. Опенов, А.И. Подливаев. ФТП 53, 724 (2019).

[43] И.Ю. Долинский, К.П. Катин, К.С. Гришаков, В.С. Прудковский, Н.И. Каргин, М.М. Маслов. ФТТ 60, 816 (2018).

[44] K.P. Katin, K.S. Grishakov, A.I. Podlivaev, M.M. Maslov. J. Chem. Theory Comp. 16, 2065 (2020).

[45] V.M. Bedanov, G.V. Gadiyak, Yu.E. Lozovik. Phys. Lett. A 109, 289 (1985).

[46] J.H. Los, K.V. Zakharchenko, M.I. Katsnelson, A. Fasolino. Phys. Rev. B 91, 045415 (2015).

[47] Л.А. Опенов, А.И. Подливаев. ФТТ 58, 821 (2016).

[48] A.J.M. Nascimento, R.W. Nunes. Nanotechnology 24, 435707 (2013).

[49] А.И. Подливаев, Л.А. Опенов. ФТТ 57, 2485 (2015).

Редактор К.В. Емцев 